$01,07,11,13$

\title{
Особенности превращения метастабильного аустенита в мартенсит деформации при лазерной наплавке порошковой проволокой 60Cr7TiAl
}

\author{
() Н.В. Гохфельд ${ }^{1}$, М.А. Филиппов ${ }^{2}$, Ю.С. Коробов ${ }^{1,2}$, С.Х. Эстемирова ${ }^{3}$, С.О. Морозов ${ }^{2}$ \\ ${ }^{1}$ Институт фризики металлов УрО РАН, \\ Екатеринбург, Россия \\ ${ }^{2}$ Уральский федеральный университет, \\ Екатеринбург, Россия \\ ${ }^{3}$ Институт металлургии УрО РАН, \\ Екатеринбург, Россия \\ E-mail: gokhfeld@imp.uran.ru
}

Поступила в Редакцию 8 июля 2021 г.

В окончательной редакции 13 июля 2021 г.

Принята к публикации 16 июля 2021 г.

Наплавки порошковой проволоки Fe-Cr-C-T-Al были выполнены лазерным, дуговым и гибридным методами. Лабораторные испытания показали, что наплавленные слои сильно различаются по износостойкости. Для выявления причин были проведены исследования металлографическим, рентгеноструктурным и дюрометрическим методами. Анализ результатов исследований показал, что причиной является разница в скоростях охлаждения наплавленного металла в диапазоне $1100-800 \mathrm{~K}$. Это различие приводит к возможности образования метастабильной аустенитной структуры, что, в свою очередь, влияет на износостойкость наплавленных слоев.

Ключевые слова: порошковая проволока, износостойкость, металлография, рентгеновская дифракция, микротвердость, лазерная наплавка, дуговая наплавка, гибридная наплавка.

DOI: 10.21883/FTT.2021.12.51651.02s

\section{1. Введение}

Сплавы на основе системы Fe-Cr-C в определенном диапазоне скоростей охлаждения, в частности, при дуговом газопламенном напылении, могут образовывать структуру метастабильного аустенита (MCA) [1]. Такая структура максимально соответствует принципу синергетического подхода к неравновесным системам. Диссипация энергии, приложенной к рабочей поверхности при внешнем локальном воздействии, наиболее эффективно осуществляется микрогетерогенной структурой с метастабильным аустенитом, который в процессе эксплуатации превращается в дисперсный мартенсит. Самоорганизация конструкции, вызванная релаксационными процессами во время образования мартенсита в результате сжимающих напряжений с высоким уровнем деформационного упрочнения поверхностного слоя обеспечивают высокое сопротивление контактному воздействию на поверхность. В процессе внешнего нагружения твердость таких сплавов увеличивается за счет наклепа аустенитно-мартенситной основы и образования деформационного мартенсита $[2,3,4,5,6]$. Эти особенности позволяют эффективно использовать материалы с МСА в износостойких приложениях в виде как основного металла [7], так и покрытий, полученных наплавкой и термическим напылением [8]. МСА перспективный материал как с точки зрения износостойкости, так и с точки зрения экономичности легирова- ния [9]. В частности, такие материалы включают сплавы $\mathrm{Fe}-\mathrm{Cr}-\mathrm{C}-\mathrm{Al}-\mathrm{Ti}[10]$. Влияние удельной погонной энергии и последующего охлаждения во время технологических операций на фазовый состав и структуру наплавленных износостойких покрытий с метастабильным аустенитом и их поведение при абразивном изнашивании требует дополнительных исследований [11]. Сварка и связанные с ней технологии широко используются в качестве технологических операций. Сварочные процессы существенно различаются по уровню подводимого тепла, например, при лазерной сварке уровень подводимого тепла на 2-3 порядка ниже, чем при дуговой сварке [12]. Это приводит к различию свойств наплавленного металла из-за степени перегрева, продолжительности пребывания в расплавленном состоянии и скорости охлаждения [9].

В зависимости от скорости охлаждения в диапазоне температур $1100-800 \mathrm{~K}$ может быть получен разный фазовый состав. Так, при низких скоростях охлаждения в углеродистой стали происходит только диффузионное разложение аустенита с образованием феррит-цементитной структуры различной степени дисперсности (перлит, сорбит, троостит). Выше критической скорости охлаждения превращение перлита становится невозможным, диффузионное разложение аустенита подавляется, а аустенит претерпевает только мартенситное превращение. Однако если скорость охлаждения намного выше критической, как в случае лазерной наплавки (эффект 
Таблица 1. Химический состав порошковой проволоки (по данным производителя)

\begin{tabular}{c|c|c|c|c|c}
\hline \multicolumn{6}{c}{ Химический состав, вес \% } \\
\hline $\mathrm{C}$ & $\mathrm{Cr}$ & $\mathrm{Al}$ & $\mathrm{Ti}$ & $\mathrm{S}$ & $\mathrm{P}$ \\
\hline 0.620 & 6.500 & 1.150 & 1.180 & 0.020 & 0.022
\end{tabular}

самозакалки), то возможно образование метастабильного аустенита [11].

Целью исследования являлось сравнить износостойкость, структуру и фазовый состав покрытий, полученных лазерным, дуговым и гибридным методами наплавки.

\section{2. Материалы, методы исследования и методика эксперимента}

Лазерная наплавка проводилась на роботизированной лазерной установке с YAG-лазерной (IPG, Россия). Гибридная наплавка осуществлялась на том же роботизированном лазерном комплексе, но с дополнительно подключенным и синхронизированным аппаратом дуговой сварки MIG (EVOMIG 350, Россия) в режиме общей плавильной ванны. Дуговая сварка TIG проводилась вручную на аппарате Lorch X 350 (Германия). В качестве защитного газа использовали аргон чистотой $99.998 \%$. Химический состав наплавляемой порошковой проволоки системы Fe-Cr-C показан в табл. 1.

Режимы наплавки подбирали таким образом, чтобы обеспечить однородное монолитное покрытие по заранее отработанным технологическим режимам, приведенным в табл. 2.

Изучение структуры проводили на растровом электронном микроскопе Quanta-200 Pegasus (FEI, Нидерланды), оборудованным системой дифракции обратно рассеянных электронов EBSD (ДОРЭ) для анализа объемной фазы аустенита или мартенсита. Индексирование образцов для EBSD анализа составляло более чем 90\%, а снижение уровня шума (экстраполяция нулевых решений) достигалось за счет применения встроенного программного обеспечения. Рентгеноструктурный и фазовый анализ проводили с помощью дифрактометра XRD-7000 (Shimadzu, Япония). Условия съемки: излучение $-\mathrm{Cu} K_{\alpha}$, графитовый монохроматор, угловой диапазон $2 \Theta=30-100^{\circ}$, тип съемки - пошаговый, шаг сканирования $0.04^{\circ}$, время в точке $-3 \mathrm{~s}$. Испытания износостойкости образцов проводили при абразивном изнашивании по закрепленному абразиву. Образцы с сечением рабочей части $10 \times 10 \mathrm{~mm}$ совершали возвратнопоступательное движение по шлифовальной бумаге на корундовой основе 14А32МН481 (ГОСТ 6456-82) со скоростью $125 \mathrm{~mm} / \mathrm{s}$ и смещением образца за один двойной ход $1.2 \mathrm{~mm}$ на общей длине пути $30 \mathrm{~m}$. Нагрузка на образцы составляла $10 \mathrm{~kg}$ (уд. нагр. $1 \mathrm{MPa}$ ). Чтобы уменьшить период притирки, рабочую поверхность $10 \times 10$ mm полировали до Ra 0.8 .

Абразивную износостойкость оценивали по результатам двух параллельных испытаний, сравнение результатов производили через относительные единицы

$$
\varepsilon=\Delta M_{e} / \Delta M_{0},
$$

где $\varepsilon-$ относительная износостойкость, $\Delta M_{e}-$ массовый износ эталонного образца, $\Delta M_{0}-$ массовый износ испытуемого образца.

В качестве эталона была взята сталь У7, с твердостью 40 единиц по Роквеллу. Пробоподготовку для анализа структуры и микротвердости осуществляли на металлографическом оборудовании QATM (Германия). Микротвердость измеряли на приборе ПМТ-3 (Ломо, Россия) при нагрузке $100 \mathrm{~g}$. Для оценки способности наплавленного покрытия к деформационному упрочнению шлифованную боковую поверхность образцов с лазерной наплавкой использовали для нанесения отпечатков на прессе Бринелля шариком диаметром $5 \mathrm{~mm}$ при нагрузке $1000 \mathrm{~kg}$. После этого на приборе Роквелла алмазом при стандартной нагрузке $150 \mathrm{~kg}$ производили измерение твердости в центре дна лунок (отпечатков), образовавшихся от внедрения шарообразных инденторов на прессе Бринелля. Отклонение от центра дна отпечатков составляло $\pm 0.5 \mathrm{~mm}$. На дне каждого отпечатка проводили только одно измерение твердости по Роквеллу.

\section{3. Результаты и обсуждение}

\section{1. Структурные исследования перед испытанием на износ}

В микроструктуре образца лазерной наплавки представлены аустенитные дендриты с вытянутыми осями первого порядка шириной 10-20 $\mu \mathrm{m}$ (рис. 1). Метал-

Таблица 2. Режимы наплавки

\begin{tabular}{l|l|c|c|c|c}
\hline Технология & Метод наплавки & Мощность $(\mathrm{kW})$ & $\begin{array}{c}\text { Скорость } \\
\text { подачи }(\mathrm{m} / \mathrm{min})\end{array}$ & $\begin{array}{c}\text { Толщина } \\
\text { слоя }(\mathrm{mm})\end{array}$ & $\begin{array}{c}\text { Дополнительные } \\
\text { параметры }\end{array}$ \\
\hline Лазер & $\begin{array}{l}\text { Роботизированная } \\
\text { лазерная }\end{array}$ & 3.5 & 2 & $4.50 \pm 0.1$ & $\begin{array}{c}\text { воблинг } \\
(1.5 \mathrm{~mm}, 300 \mathrm{~Hz})\end{array}$ \\
\hline Дуга & Ручная TIG & 5 & 2 & $4 \pm 0.1$ & Общий ванна расплава \\
\hline Гибрид & Лазер + MIG & $2+3$ & 2 & $6 \pm 0.1$ & Общая ванна расплава
\end{tabular}




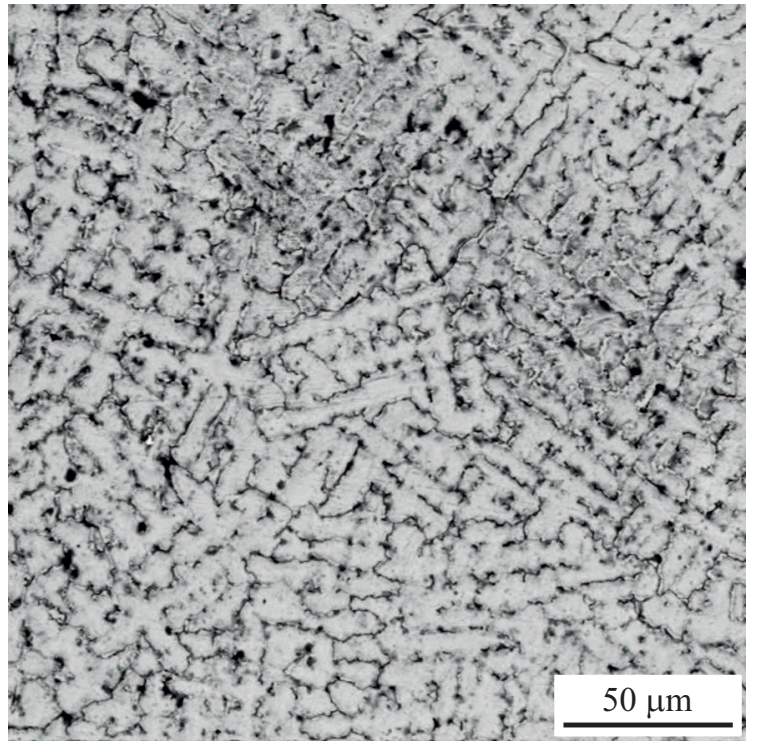

Рис. 1. Микроструктура лазерной наплавки в плоскости поперечного сечения.

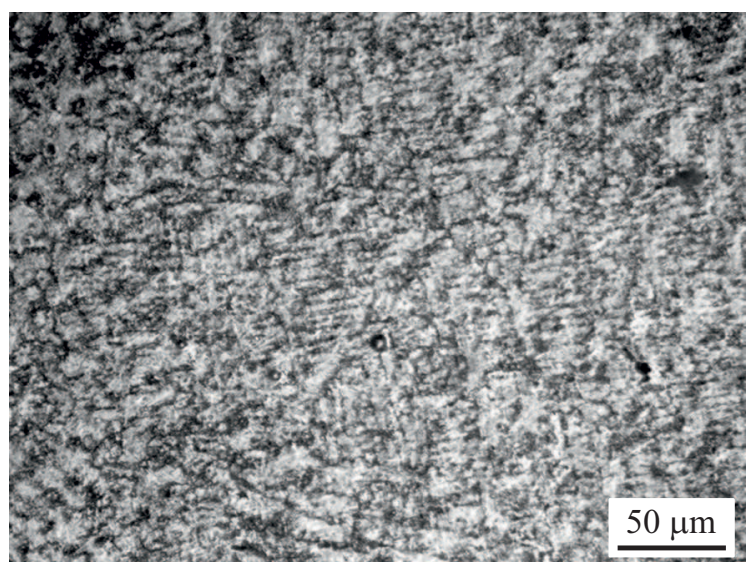

Pис. 2. Микроструктура дуговой наплавки в плоскости поперечного сечения.

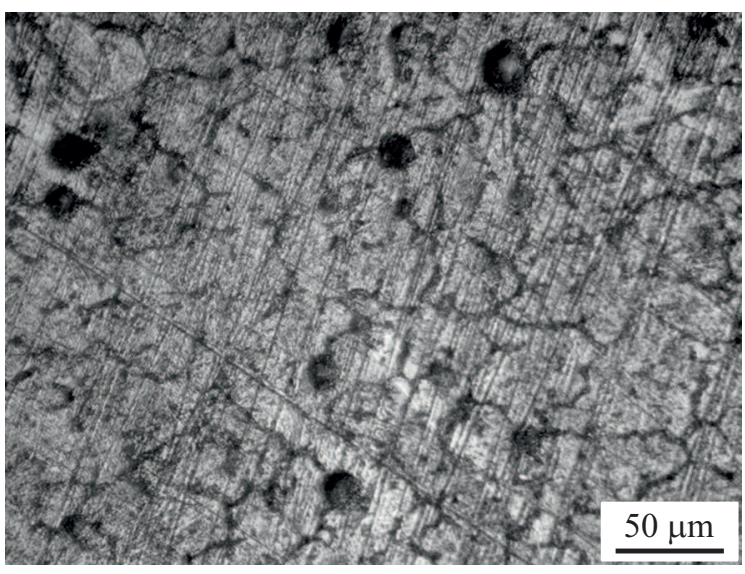

Рис. 3. Микроструктура гибридной наплавки в плоскости поперечного сечения. лографический анализ поверхностных слоев лазерной наплавки показал, что структура подобна структуре стали 50Х18 [13].

Структура сплава после дуговой наплавки представляет собой дендритно-ячеистую структуру с граничными выделениями сети дисперсных, очевидно эвтектических, карбонитридов и мартенситных кристаллов внутри равноосных зерен неоднородных размеров со средним диаметром 10-15 $\mu \mathrm{m}$, имеющих мартенситную структуру (рис. 2). Пластинчатые кристаллы мартенсита образуют рельеф в виде параллельных полос в пределах одного зерна аустенита.

Гибридная наплавка имеет дендритно-ячеистую структуру с граничными выделениями, подобную дуговой наплавке, с более крупными зернами-ячейками со средним диаметром 20-100 $\mu$ m и кристаллами мартенсита внутри зерен, образующими также полосчатый рельеф в виде параллельных полосок параллельной ориентировки внутри одного зерна (рис. 3).

\section{2. Измерение твердости перед испытанием на износ}

Если в случае дуговой и гибридной технологии наплавки образуется мартенситная структура, то в результате использования лазера для наплавки получается структура, состоящая из метастабильного аустенита [14].

Из рис. 4 видно, что твердость дуговой и гибридной наплавок намного выше, чем в случае использования лазерной технологии наплавки, что, вероятно, обусловлено различием в структуре, описанным выше.

\section{3. Рентгеновские исследования перед испытанием на износ}

Фазовый состав и параметры элементарной ячейки для всех технологий наплавок перед испытаниями на износ приведены табл. 3.

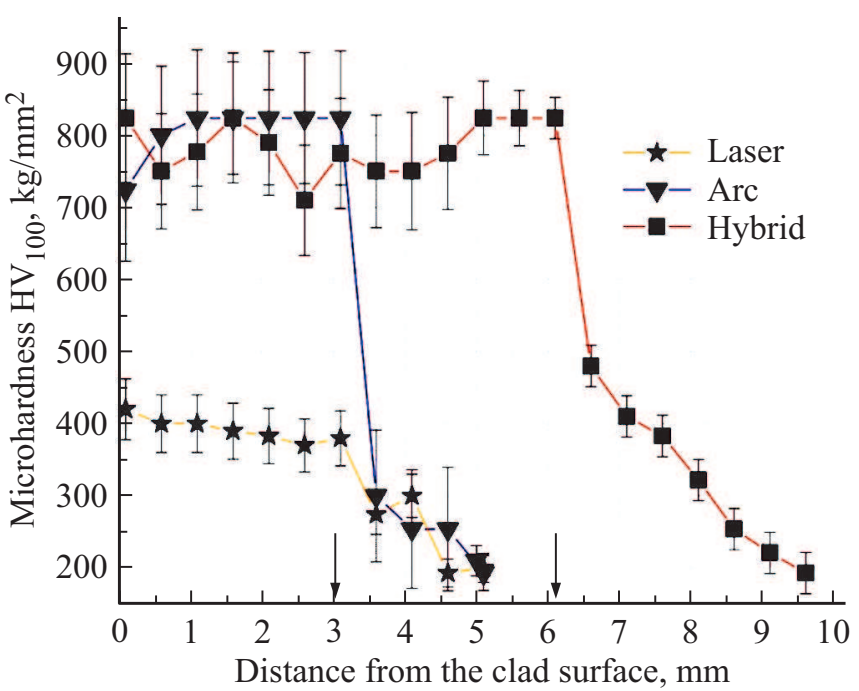

Pис. 4. Микротвердость профиля наплавки $\mathrm{HV}_{100}$. 
Таблица 3. Фазовый состав и параметры элементарной ячейки до испытаний на износ

\begin{tabular}{|c|c|c|c|}
\hline \multirow{2}{*}{ Образец } & \multirow{2}{*}{ Фазовый состав } & \multicolumn{2}{|c|}{ Параметры элементарной ячейки } \\
\hline & & $a, \AA$ & $V, \AA^{3}$ \\
\hline \multirow{2}{*}{ Лазер } & $\gamma-\mathrm{Fe}(F m-3 m)(>98 \%)$ & 3.5900 & 46.269 \\
\hline & $\alpha-\mathrm{Fe}(\operatorname{Im}-3 m)(<2 \%)$ & 2.8624 & 23.5 \\
\hline \multirow{2}{*}{ Дуга } & $\gamma-\mathrm{Fe}(F m-3 m)(>9 \%)$ & 3.6209 & 47.473 \\
\hline & $\alpha-\mathrm{Fe}(\operatorname{Im}-3 m)(<91 \%)$ & 2.8939 & 24.236 \\
\hline \multirow{3}{*}{ Гибрид } & $\gamma-\mathrm{Fe}(F m-3 m)(>4 \%)$ & 3.6174 & 47.334 \\
\hline & $\alpha-\mathrm{Fe}(\operatorname{Im}-3 m)(<94 \%)$ & 2.8959 & 24.285 \\
\hline & езо-хромистый карбид < 2\% & & \\
\hline
\end{tabular}

Таблица 4. Испытания на износ

\begin{tabular}{l|c|c|c|c}
\hline Образец & $\Delta M, \mathrm{~g}$ & $\varepsilon$ & $H R C$ & $\mathrm{HV}_{50}$ износ \\
\hline Лазер & 0.240 & 3.17 & 35 & 770 \\
\hline Дуга & 0.190 & 4.00 & 60 & 890 \\
\hline Гибрид & 0.260 & 2.92 & 52 & 744
\end{tabular}

Как видно из рентгенограмм (рис. 5), в случае дуговой и гибридной наплавок наблюдается уширение пиков, что свидетельствует о дефектности структуры. В случае же лазерной наплавки уширения пиков минимальны.

На рис. 6 построены карты фазовых распределений на поверхности поперечного сечения исследуемых наплавленных различными методами покрытий. Видно, что при использовании метода лазерной наплавки (рис. $6, a$ ) около 88\% покрытия составляет аустенит с большим размером зерна в диапазоне $50-150 \mu \mathrm{m}$. Размер зерна образца после дуговой наплавки меньше (в пределах 1-50 $\mu \mathrm{m})$, фаза составляет более 84 процентов мартен-

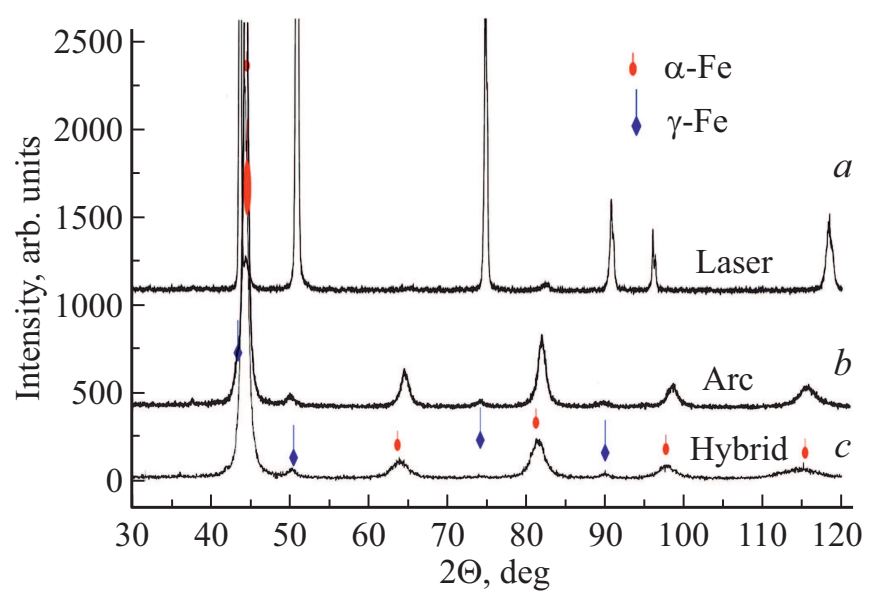

Рис. 5. Рентгенограммы наплавок до испытаний на износ. сита (рис. 6, $b$ ). Как обсуждалось ранее, из-за высокого тепловложения при гибридной наплавке и дуговой технологии наплавки выше, происходит фазовый переход в мартенсит, что подтверждает EBSD анализ (рис. $6, b, c)$, как и наличие большого количества аустенитной фазы при лазерной наплавке (рис. 6,a). Также карты фазового распределения подтверждают результаты рентгеновского анализа (см. рис. 5).

\section{4. Исследования после испытаний на износ}

Результаты испытаний на абразивный износ исследуемых сталей приведены в табл. 4.

Из данных таблицы видно, что способность к упрочнению рабочей поверхности лазерной наплавки, оцениваемая по микротвердости после изнашивания, превышает таковую после гибридной наплавки, что обусловлено образованием дисперсных кристаллов мартенсита деформации под воздействием движущихся абразивных частиц. Для того, чтобы доказать метастабильные свойства аустенита, после деформационно-индуцированного фазового перехода в мартенсит, была измерена твердость по Роквеллу после деформации на дне отпечатка, полученного на прессе Бринелля от вдавливания шарика, согласно значениям описаным в методике (см. выше). Микроструктура под отпечатком от шарика подобна мартенситу в виде колоний параллельных пластинок, шириной 2-5 $\mu \mathrm{m}$ (рис. 7).

По-видимому, волновой характер расположения кристаллов мартенсита деформации в виде параллельных пластин обусловлен формированием чередующихся пиков сжимающих напряжений на фронте движущегося индентора (или абразивных частиц при абразивном изнашивании [15] и растягивающих напряжений после прохождения индентора (частицы) в данном микрообъеме металла (рис. 7). Кристаллы мартенсита с большим удельным объемом по сравнению с аустенитом образуются в тех участках аустенита, где пиковые напряжения растяжения превышают критическую 


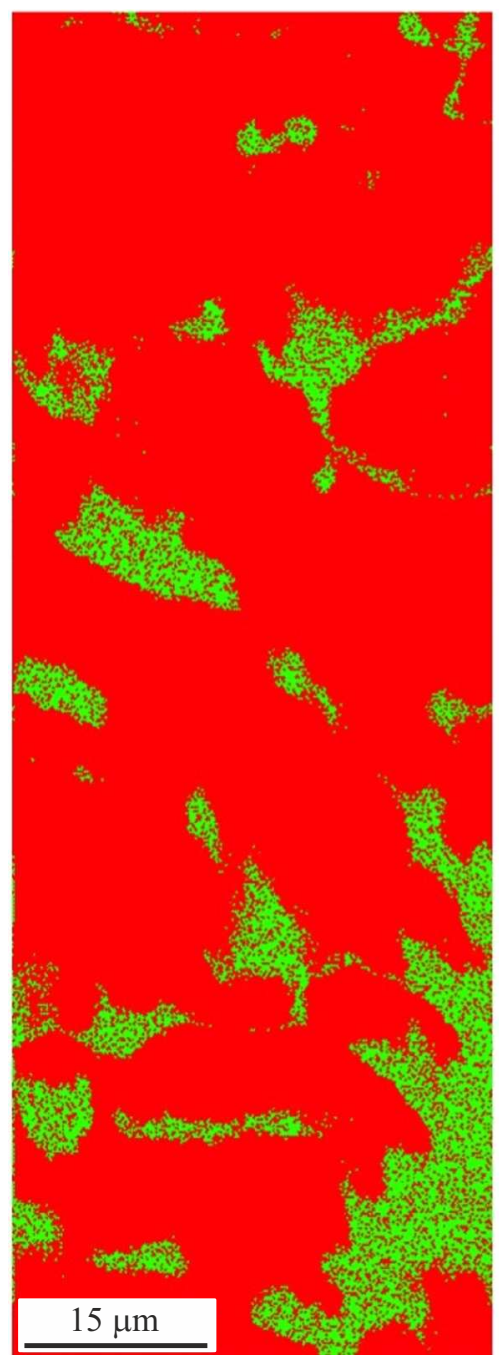

Total
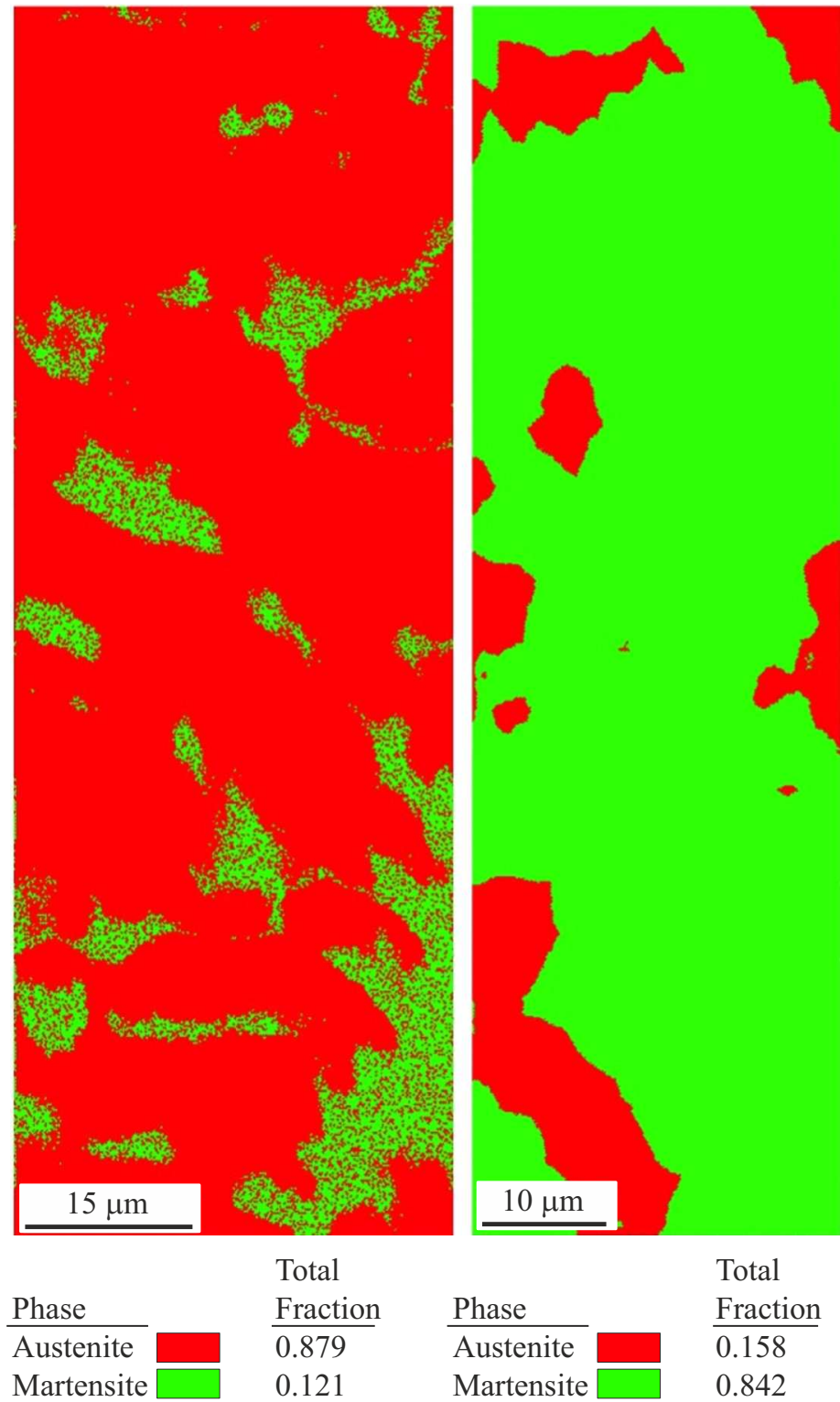

$b$

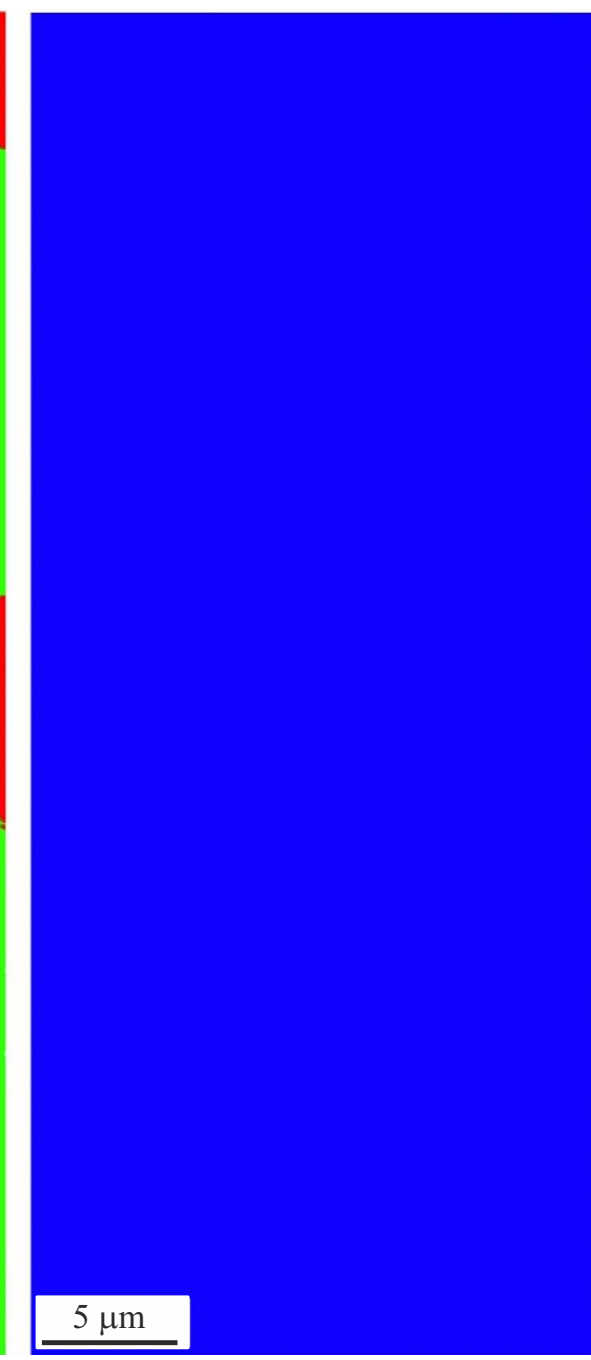

Total

Fraction

Pис. 6. EBSD-карта распределения фаз в наплавках до испытаний на износ: a) лазер, b) дуга, с) гибрид.

величину сдвига при мартенситном превращении. Образование кристаллов мартенсита деформации сопровождается микротрип-эффектом [14]. Поскольку представленная на рис. 7 микроструктура получена от одного зерна аустенита при деформации, то расположение кристаллов мартенсита деформации правильными параллельными колониями в разных зернах можно объяснить действием однородного поля напряжений при одинаковой ориентации кристаллической решетки аустенита. Армирование поверхности дисперсными кристаллами мартенсита, стимулирующими микро-трип эффект и релаксацию микронапряжений в момент сдвига, затрудняет внедрение индентора или абразивных частиц, повышая сопротивление внедрению индентора или изнашиванию.
Твердость внутри отпечатка возросла на $20 \mathrm{HRC}$ от исходной и составила $58 \mathrm{HRC}$, что по величине близко соответствует таковой, полученной по гибридной технологии наплавки (табл. 3). Величина такого увеличения твердости чрезмерна для деформационного упрочнения и подтверждает наличие мартенситного превращения.

На дифрактограмме также видны рефлексы примесных фаз (рис. 8), предположительно, один из пиков (в районе $42^{\circ}$ ) принадлежит фазе $\mathrm{Fe}_{2} \mathrm{C}$, орторомбической системе, пространственной группе Рnпm.

Фазовый состав и параметры элементарной ячейки показаны на рис. 8 (см. вставку). Результаты рентгенофазового анализа также подтверждают, что эти многочисленные полосы представляют собой поперечное сечение дисперсных мартенситных кристаллов, образовавшихся 

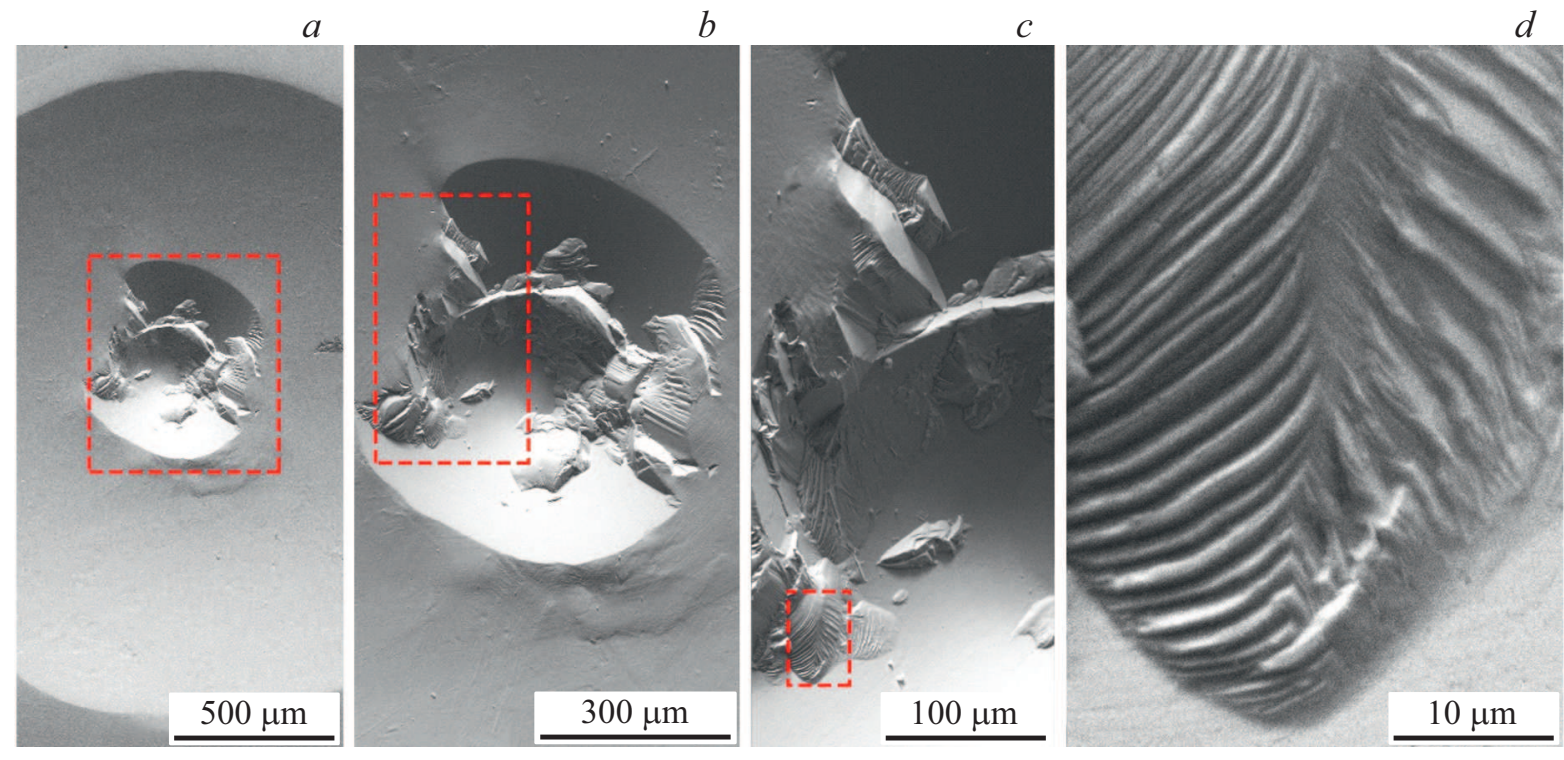

Рис. 7. Микроструктура внутри отпечатка шарика на лазерной наплавке.

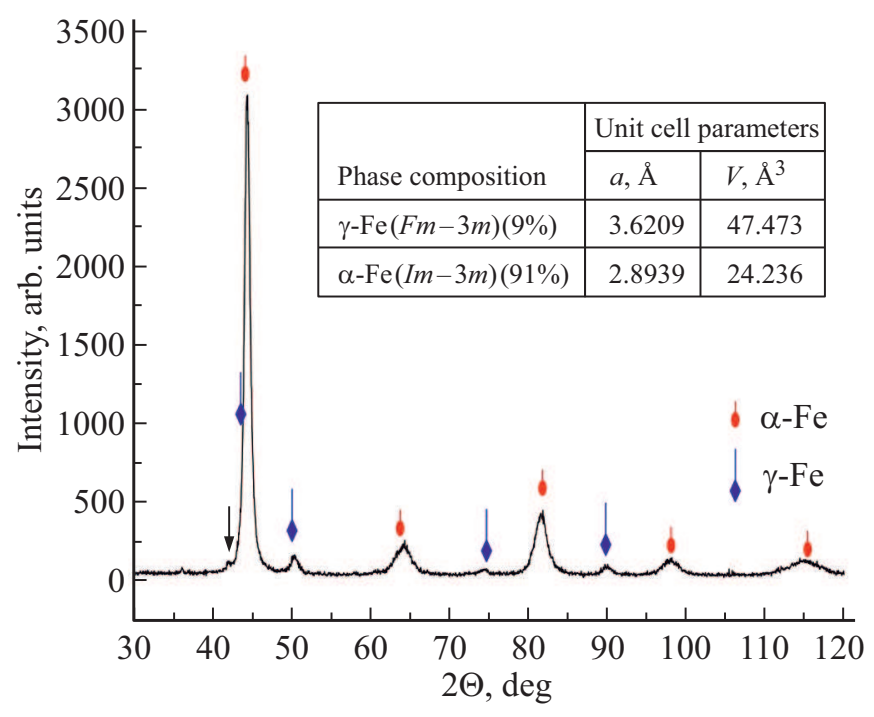

Рис. 8. Рентгенограммы лазерной наплавки после испытаний на износ.

в процессе абразивного износа. Уширение пиков, также как и на рис. 5 подтверждает наличие дефектной мартенситной структуры.

\section{4. Заключение}

На основании сравнения износостойкости покрытий установлено, что относительная износостойкость для лазерной наплавки составляет 3.17 , что оказалось даже выше, чем при гибридной наплавке (2.92). Обнаружено, что под действием деформации или изнашивания метастабильный аустенит переходит в мартенсит с твер- достью, соответствующей покрытиям, нанесенным дуговым и гибридным методами.

Высокая износостойкость покрытия, полученного лазерной технологией наплавки, оказалась выше, чем у гибридной, хотя у лазерной наплавки твердость значительно ниже $\left(375 \mathrm{HV}_{100}\right)$, чем у гибридной $\left(775 \mathrm{HV}_{100}\right)$ и дуговой наплавки $\left(810 \mathrm{HV}_{100}\right)$. Износостойкость лазерной наплавки одного уровня с дуговой наплавкой обусловлена деформационным мартенситным превращением метастабильного аустенита. До нагружения исходная твердость покрытия, наплавленного лазерной технологией, составляла около $38 \mathrm{HRC}$, а после нагружения составила $58 \mathrm{HRC}$, таким образов твердость возросла примерно на 20HRC при этом объем MCA фазы, согласно данным рентгеновского анализа, до нагружения составил около 98\% и всего лишь 9\% после нагружения.

\section{Финансирование работы}

Работа выполнена в рамках государственного задания ФАНО России для ИФМ УрО РАН по теме № ААААА19-119070490049-8 и поддержана грантом Фонда содействия инновациям (проект IRA-SME № 58674).

\section{Конфликт интересов}

Авторы заявляют, что у них нет конфликта интересов.

\section{Список литературы}

[1] Y. Korobov, M. Filippov, A. Makarov, I. Malygina, N. Soboleva, D. Fan-tozzi, M. Andrea, H. Koivuluoto, P. Vuoristo. Coatings 8, 2 (2018).

[2] G. Olson, M. Cohen. J. Less Common Met. 28, 1, 107 (1972). 
[3] C. Wayman. Martensitic transformations: Electron microscopy and diffraction studies. In: Diffraction and Imaging Techniques in Material Science / Eds S. Amelinckx, R. Gevers, J. Van Landuyt. $2^{\text {nd }}$ ed. (1978).

[4] Z. Shi, W. Shao, L. Rao, T. Hu, X. Xing, Y. Zhou, S. Liu, Q. Yang. Appl. Surface Sci. 538, 148108 (2021).

[5] S. Atamert, H. Bhadeshia. Mater. Sci. Eng. A 130, 1, 101 (1990).

[6] Y. Korobov, V. Verkhorubov, S. Nevezhin, M. Filippov, A. Tkachuk, A. Makarov, I. Zabolotskikh. An influence of strain-induced nucleation of martensitic transformation on tribogical properties of sprayed and surfaced depositions. International Thermal Spray Conference and Exposition 8, 684 (2016).

[7] M.A. Filippov, G. Yagudin, V. Legchilo, M. Khadiyev, N. Ozerets, S. Estemirova. The use of metastable austenite to increase the wear resistance of steels of the pearlite class. In: Materials Engineering and Technologies for Production and Processing IV. V. 284 of Solid State Phenomena, Trans Tech Publications Ltd. (2018).

[8] A. Pukasiewicz, H. de Boer, G. Sucharski, R. Vaz, L. Procopiak. Surface Coatings Technology 327 (2017).

[9] I. Korobov, O. Pimenova, M. Filippov, M. Khadyev, N. Ozerets, S. Mikhailov, S. Morozov, I. Davydov, N. Razikov. Procedia Structural Integrity 14, 34 (2019).

[10] Ю.С. Коробов, В.И. Шумяков, В.Е. Прохорович и др. Патент № 2692145 С1 Российская Федерация, МПК В23К 35/30, С22С 38/28. Проволока для сварки среднеуглеродистых среднелегированных броневых сталей: № 2017144969. Заявл. 20.12.2017. Опубл. 21.06.2019. Заявитель Уральский федеральный ун-т.

[11] G. Fargas, J. Roa, A. Mateo. Wear 364-365, 40 (2016).

[12] J. Zhou, H. Tsai. In: Processes and Mechanisms of Welding Residual Stress and Distortion, Woodhead Publishing Series in Welding and Other Joining Technologies / Ed. Z. Feng. Woodhead Publishing (2005).

[13] G.R. Desale, C. Paul, B. Gandhi, S. Jain. Wear 266, 9 (2009).

[14] М.Л. Бернштейн, В.А. Займовский, Л.М. Капуткина. Термомеханическая обработка стали. Металлургия, М. (1983). $231 \mathrm{c}$.

[15] S.M. Nikiforova, M.A. Filippov, A.S. Zhilin. Solid State Phenomena 265, 10 (2017).

Редактор Д.В. Жуманов 